\title{
An assessment of a Simple Hardness Kernel Approximation for the Calculation of the Global Hardness in a series of Lewis acids and bases $^{\dagger}$
}

\author{
Miquel Torrent-Sucarrat, Josep Maria Luis, Miquel Duran, and Miquel Solà* \\ Institut de Química Computacional and Departament de Química, Universitat de Girona, \\ E-17071 Girona, Catalonia, Spain.
}

\begin{abstract}
A simplified model of the hardness kernel, $\eta\left(\vec{r}, \vec{r}^{\prime}\right) \cong \delta\left(\vec{r}-\vec{r}^{\prime}\right)$, has been evaluated for the calculation of the global hardness in a series of Lewis acids and bases using the MP2 method. It is found that this simple model yields the appropriate ordering of the molecules according to their hardness values when compared to experimental available results.
\end{abstract}

Key words: Conceptual density functional theory (DFT), chemical hardness, Fukui functions, quantum molecular similarity measures, ionization potential, electron affinity, HOMO and LUMO energies, Lewis acids and bases. 


\section{INTRODUCTION}

Density functional theory (DFT) [1] is a form of quantum mechanics that uses the oneelectron density function, $\rho$, instead of the more usual wave function, $\Psi$, to describe a chemical system. Such a system is any collection of nuclei and electrons.

During the last decade, the role of DFT in quantum chemistry has shown a rapid increase. With these methods, it is possible to include electron correlation at a much lower computational cost than using conventional $a b$ initio correlation methods. Another important aspect of DFT, besides computational advantages, is the fact many commonly used chemical concepts, such as the electronegativity $(\chi)$ [2], the global hardness $(\eta)$ [3], and the global softness $(S)$ [4] receive a precise mathematical definition. In this respect, DFT provides a bridge that connects some traditional empirical concepts with quantum mechanics [1,5]. Among these common concepts, the hardness is especially significant since it is the cornerstone of some important principles of chemical reactivity such as the hard and soft acids and bases (HSAB) [3,6,7] principle and the maximum hardness principle (MHP) [3,6-9].

Besides the global parameters $(\chi, \eta$, and $S)[1]$, a number of local counterparts (e.g. the local hardness $\eta(\vec{r})[10,11]$, the local softness $s(\vec{r})[10,11]$, and the Fukui function $f(\vec{r})$ [12]) have been developed. These local functions have become very useful to predict the regioselectivity of intermolecular and intramolecular reactions [13].

\subsection{The original definition of hardness}

Pearson introduced the concepts of hard and soft acids/bases and the HSAB principle. This principle asserts that hard acids prefer to coordinate with hard bases, while 
the soft acids prefer to react with soft bases from both the thermodynamic and kinetic points of view.

TABLE 1 and 2 here

Tables 1 and 2 [3] show the first classification between hard and soft bases/acids. A soft base, e.g. $\mathrm{I}^{-}$, is very polarizable, easily oxidized and it has a low electronegativity; while a hard base, e.g. $\mathrm{F}^{-}$, is not much polarizable, hard to oxidize and it has a high electronegativity. A soft acid, e.g. $\mathrm{Rb}^{+}$, is usually a system of low positive charge and large size; while a hard acid, e.g. $\mathrm{Al}^{3+}$, is normally a system of high positive charge and small size. Generally, a hard acid or base is a system with an electron cloud difficult to deform.

The classification of Tables 1 and 2 is qualitative. We know according to factors of charge, size, and charge distribution that, for instance, as a base the hydroxy anion is harder than the water molecule. Such simple qualitative relationships are very important. However, even more important is to be able to quantify their hardness to determine numerically how much harder is the hydroxy ion as compared to water.

\subsection{DFT-based global hardness and softness}

Parr and Pearson [6] first provided the analytical definition of global hardness of any chemical species as the second-order partial derivative of the total electronic energy, $E$, with respect to the total electron number of electrons, $N$, at a fixed external potential $v(\vec{r})$ :

$$
\eta=\left(\frac{\partial^{2} E}{\partial N^{2}}\right)_{v(\vec{r})}=\left(\frac{\partial \mu}{\partial N}\right)_{v(\vec{r})}=-\left(\frac{\partial \chi}{\partial N}\right)_{v(\vec{r})} .
$$

Here $v(\vec{r})$ is the potential acting on an electron at $\vec{r}$ due to the nuclear attraction plus such other external forces as may be present. The term $\mu$ is the electronic chemical 
potential, which is the negative of the electronegativity $(\chi)$ [14], as defined by Iczkowski and Margrave [15].

Hardness [16-18] is a measure of the resistance of a chemical species to change its electronic configuration, while electronic chemical potential measures the escaping tendency of an electron cloud. The reciprocal of the hardness is the softness [16-18], which measures the easiness of charge transfer and it is associated with high polarizability [19],

$$
S=\frac{1}{\eta}
$$

By applying the finite-difference approximation to Eq. (1), we get the operational definition of $\eta$ as [16-18],

$$
\eta \cong I-A
$$

where $I$ and $A$ are the vertical ionization energy and electron affinity, respectively. These quantities can be directly obtained from Hartree-Fock (HF) molecular orbital calculations following the Koopmans’ theorem [20]. For closed-shell species one has,

$$
\eta \cong \varepsilon_{\text {LUMO }}-\varepsilon_{\text {HОMO }}
$$

where $\varepsilon_{\text {HOMO and }} \varepsilon_{\text {LUMO }}$ are the energies of the highest occupied molecular orbital and the lowest unoccupied molecular orbital, respectively.

Experimentally, the most difficult problem in Eq. (3) is usually to measure precise electron affinities. The reason is that most molecules have negative electron affinities and energy is required to force an electron on to the molecule. To measure such vertical negative electron affinities, the electron transmission spectroscopy technique has been devised [21].

When experimental values of $I$ and $A$ are lacking, it is necessary to use the theory. Calculation of hardness from Eqs. (3) and (4) is subject to several error sources [22], the 
most important being the fact that the finite difference approximation in Eq. (1) has been used to derive Eqs. (3) and (4) and this approximation can only be strictly applied using an integer number of electrons $(\Delta N= \pm 1)$ [23-25]. For this reason, it is very important to explore new ways to compute more accurate hardnesses [26] and this will be the main goal of the present work.

\subsection{Fukui functions}

Another reactivity index based on DFT is the Fukui function [12], first introduced in the 1980s by Yang and Parr. They defined the Fukui function, $f(\vec{r})$, as the partial derivative of $\rho(\vec{r})$ with respect to the number of electrons, at constant external potential $v(\vec{r})$. A Maxwell-like relation links the chemical potential $\mu$ and $f(\vec{r})$ as,

$$
f(\vec{r})=\left(\frac{\partial \rho(\vec{r})}{\partial N}\right)_{v(\vec{r})}=\left(\frac{\partial \mu}{\partial v(\vec{r})}\right)_{N} .
$$

The Fukui function describes the local alteration in the electron density of the system due to a change in the global number of electrons, so it reflects the character of a reactant to accept (donate) electrons from (to) another system, and as such it constitutes an important reactivity index.

For a molecular or atomic system, the derivative of Eq. (5) is discontinuous [23-25] and difficult to evaluate. Consequently, Yang and Parr have provided three definitions for Fukui functions [12], corresponding to a reactivity index for a nucleophilic $f^{+}(\vec{r})$, electrophilic $f^{-}(\vec{r})$, and radical $f^{o}(\vec{r})$ attacks on the system, where is possible to apply the finite difference approximation in density [27], and the frontier electron-theory of reactivity as formulated by Fukui and collaborators [28]: 


$$
\begin{gathered}
f^{+}(\vec{r})=\left(\frac{\partial \rho(\vec{r})}{\partial N}\right)_{V(\vec{r})}^{+}=\rho_{N+1}(\vec{r})-\rho_{N}(\vec{r}) \cong \rho_{\text {LUMO }}(\vec{r}), \\
f^{-}(\vec{r})=\left(\frac{\partial \rho(\vec{r})}{\partial N}\right)_{V(\vec{r})}^{-}=\rho_{N}(\vec{r})-\rho_{N-1}(\vec{r}) \cong \rho_{\text {НОмО }}(\vec{r}), \text { and } \\
f^{0}(\vec{r})=\frac{1}{2}\left(f^{+}(\vec{r})+f^{-}(\vec{r})\right)=\frac{1}{2}\left[\rho_{N+1}(\vec{r})-\rho_{N-1}(\vec{r})\right] \cong \frac{1}{2}\left[\rho_{\text {LUMO }}(\vec{r})+\rho_{\text {номо }}(\vec{r})\right],
\end{gathered}
$$

where the superscripts -, +, and 0 refer to the left, right, and central derivatives,

respectively. $\rho_{N+1}(\vec{r}), \rho_{N}(\vec{r})$, and $\rho_{N-1}(\vec{r})$ are the electronic densities of the system with $N+1, N$, and $N-1$ electrons, respectively.

\subsection{The relation between Fukui functions and hardness}

An alternative to Eqs. (3) and (4) is to use the following expression first formulated by Ghosh [29] and later on mathematically demonstrated by Chattaraj et al. [30]:

$$
\eta=\iint f(\vec{r}) \eta\left(\vec{r}, \vec{r}^{\prime}\right) f\left(\vec{r}^{\prime}\right) d \vec{r} d \vec{r}^{\prime}
$$

In Eq. (9), $f(\vec{r})$ is the Fukui function as defined by Eq. (5). Obviously, Eq. (9) can be applied with the Fukui functions defined by Eqs. (6) to (8), although these equations have been derived using the finite difference approximation and therefore the $\Delta N= \pm 1$ drawback is still present. It is worth noting that analytical definitions for the Fukui function that avoid this problem have been developed and they are good alternatives for the commonly used Eqs. (6) to (8) [31]. On the other hand, $\eta\left(\vec{r}, \vec{r}^{\prime}\right)$ [11] is the hardness kernel, from which most reactivity parameters in DFT can be readily defined [32]. This hardness kernel is defined as the second order functional derivative of Hohenberg-Kohn universal density functional ( $F[\rho]$ ) with respect to the density, 


$$
\eta\left(\vec{r}, \vec{r}^{\prime}\right)=\frac{\delta^{2} F[\rho]}{\delta \rho(\vec{r}) \delta \rho\left(\vec{r}^{\prime}\right)} .
$$

In Eq. (10), $F[\rho]$ is an unknown and presumably very complicated functional that contains the kinetic energy density functional, the classical electron-electron Coulomb repulsion functional, and the exchange-correlation functional:

$$
F[\rho]=T[\rho]+J[\rho]+E_{x c}[\rho] .
$$

The drawback of the Eq. (11) is that the exact expressions for $T[\rho]$ and $E_{X C}[\rho]$ are unknown. One can employ, however, the approximate available expressions. For instance, using the Thomas-Fermi form [33] for the kinetic energy density functional, the Dirac exchange energy functional [34] for the exchange-correlation functional, and the exact form of the classical Coulomb repulsion functional, one gets [35]:

$$
\eta\left(\vec{r}, \vec{r}^{\prime}\right) \cong \frac{1}{\left|\vec{r}-\vec{r}^{\prime}\right|}+\frac{10}{9} c_{T} \rho^{-\frac{1}{3}}(\vec{r}) \delta\left(\vec{r}-\vec{r}^{\prime}\right)+\frac{4}{9} c_{X} \rho^{-\frac{2}{3}}(\vec{r}) \delta\left(\vec{r}-\vec{r}^{\prime}\right) .
$$

Then, from Eq. (12), it is possible to write a more compact expression of the hardness kernel as [32]:

$$
\eta\left(\vec{r}, \vec{r}^{\prime}\right) \cong \frac{1}{\left|\vec{r}-\vec{r}^{\prime}\right|}+g(\vec{r}) \delta\left(\vec{r}-\vec{r}^{\prime}\right)
$$

where the first term originates from the classical Coulombic repulsion term, while the second comes from the kinetic and exchange and correlation terms. Far away from the nuclei and because of the exponential fall-off of the density, the exchange-correlation can be neglected and the leading term arises from the Coulombic contribution [5,11,35-39], so that:

$$
\eta\left(\vec{r}, \vec{r}^{\prime}\right) \cong \frac{1}{\left|\vec{r}-\vec{r}^{\prime}\right|}
$$


Introducing this approximation into Eq. (9), one obtains:

$$
\eta=\iint f(\vec{r}) \frac{1}{\left|\vec{r}-\vec{r}^{\prime}\right|} f\left(\vec{r}^{\prime}\right) d \vec{r} d \vec{r}^{\prime}
$$

An even more simplified approximation to the hardness kernel could be:

$$
\eta\left(\vec{r}, \vec{r}^{\prime}\right) \cong \delta\left(\vec{r}-\vec{r}^{\prime}\right)
$$

where Eq. (16) is derived from Eq. (13) by approximating the Coulombic term, $1 /|\vec{r}-\vec{r}|$, to a Dirac delta function, $\delta\left(\vec{r}-\vec{r}^{\prime}\right)$, and assuming that $g(\vec{r})$ is constant. This is probably the simplest model that one can conceive for the hardness kernel. Substitution in Eq. (9) leads to the following very simple and computationally cheap form for the hardness:

$$
\eta=\int f^{2}(\vec{r}) d \vec{r}
$$

Eq. (15) was used by Liu, Proft, and Parr [39] for the calculation of the global hardness of the first 54 neutral atoms. The authors showed that Eq. (15) generates reasonable atomic global hardness values. On the other hand, in our previous work [40], we have tested the two simplified models of the hardness kernel (Eqs. (14) and (16)) to calculate the global hardness for a series of 18 neutral Lewis bases using the hybrid B3LYP functional and conventional $a b$ initio correlated methods. In this study, we find that the cheapest model (Eq. (16)) yields the best molecular orderings by hardness when compared to experimental values. However, it is important to remark that despite the success of this simple model in ordering the molecules by hardness, this approximation does not provide correct estimates of global hardnesses [40]. Finally, it is worth nothing that the use of this approximation produces some inconsistencies. For instance, using $\eta\left(\vec{r}, \vec{r}^{\prime}\right) \cong \delta\left(\vec{r}-\vec{r}^{\prime}\right)$ the global softness cannot be defined [40]. 
The goal of this paper is to continue the work of our previous study on 18 neutral Lewis bases [40] and to show that Eq. (17) can provide the intuitive (or experimental when available) molecular ordering by hardness in a series of Lewis acids (both cations and neutral molecules) and Lewis bases (anions). Anions are especially interesting since the measure of their experimental hardness is usually very difficult.

\subsection{Quantum molecular similarity measures}

The quantum molecular similarity measures (QMSM) quantify how similar one molecule is to another and for that reason they are useful parameters in studies of charge density redistributions [41] and quantitative structure activity relationship (QSAR) analysis [42]. One of the most widely used quantum molecular similarity definitions between two molecules $A$ and $B$ of densities $\rho_{A}(\vec{r})$ and $\rho_{B}\left(\vec{r}^{\prime}\right)$ was first reported in a landmark study by Professor Carbó-Dorca and collaborators [43,44] who showed that their similarity is given by,

$$
\mathrm{Z}_{A, B}(\Theta)=\iint \rho_{A}(\vec{r}) \Theta\left(\vec{r}, \vec{r}^{\prime}\right) \rho_{B}\left(\vec{r}^{\prime}\right) d \vec{r} d \vec{r}^{\prime},
$$

$\Theta\left(\vec{r}, \vec{r}^{\prime}\right)$ being an operator depending on two-electron coordinates. Overlap-like QMSMs are obtained when the $\Theta\left(\vec{r}, \vec{r}^{\prime}\right)$ is chosen as a Dirac delta function, $\delta\left(\vec{r}-\vec{r}^{\prime}\right)$, while the use of the operator $1 /\left|\vec{r}-\vec{r}^{\prime}\right|$ or $1 /\left|\vec{r}-\vec{r}^{\prime}\right|^{2}$ gives rise to Coulomb-like QMSMs and gravitationallike QMSMs, respectively [44].

In the particular case that $\rho_{A}(\vec{r})=\rho_{B}\left(\vec{r}^{\prime}\right)$ one gets the so-called quantum molecular self-similarity of a particular molecule $A, Z_{A, A}(\Theta)$, which is very useful to quantify electron charge concentration [45]. 


\section{COMPUTATIONAL DETAILS}

Eqs. (15) and (17) can be generalized using the following expression:

$$
\eta=\iint f(\vec{r}) \Theta\left(\vec{r}, \vec{r}^{\prime}\right) f\left(\vec{r}^{\prime}\right) d \vec{r} d \vec{r}^{\prime}
$$

In this formula $\Theta\left(\vec{r}, \vec{r}^{\prime}\right)$ is a Dirac delta function $\delta\left(\vec{r}-\vec{r}^{\prime}\right)$ or the operator $1 /\left|\vec{r}-\vec{r}^{\prime}\right|$. Introducing the three definitions of Fukui functions (Eqs. (6) to (8)) into Eq. (19)), one could establish three different definitions of hardness for electrophilic, nucleophilic, and radical attacks [30]:

$$
\begin{gathered}
\eta_{f^{-} f^{-}}(\Theta)=\iint f^{-}(r) \Theta\left(r, r^{\prime}\right) f^{-}\left(r^{\prime}\right) d r^{\prime} d r^{\prime}=\iint\left(\rho_{N}(r)-\rho_{N-1}(r)\right) \Theta\left(r, r^{\prime}\right)\left(\rho_{N}\left(r^{\prime}\right)-\rho_{N-1}\left(r^{\prime}\right)\right) d r d r^{\prime} \\
=\iint \rho_{N}(r) \Theta\left(r, r^{\prime}\right) \rho_{N}\left(r^{\prime}\right) d r^{\prime} d r^{\prime}+\iint \rho_{N-1}(r) \Theta\left(r, r^{\prime}\right) \rho_{N-1}\left(r^{\prime}\right) d r d r^{\prime}-2 \iint \rho_{N}(r) \Theta\left(r, r^{\prime}\right) \rho_{N-1}\left(r^{\prime}\right) d r d r^{\prime}, \\
\eta_{f^{+} f^{+}}(\Theta)=\iint f^{+}(r) \Theta\left(r, r^{\prime}\right) f^{+}\left(r^{\prime}\right) d r^{\prime} d r^{\prime}=\iint\left(\rho_{N+1}\left(r^{\prime}\right)-\rho_{N}(r)\right) \Theta\left(r, r^{\prime}\right)\left(\rho_{N+1}\left(r^{\prime}\right)-\rho_{N}\left(r^{\prime}\right)\right) d r d r^{\prime} \\
=\iint \rho_{N+1}(\vec{r}) \Theta\left(\vec{r}, \vec{r}^{\prime}\right) \rho_{N+1}\left(\vec{r}^{\prime}\right) d \vec{r} d \vec{r}^{\prime}+\iint \rho_{N}(\vec{r}) \Theta\left(\vec{r}, \vec{r}^{\prime}\right) \rho_{N}\left(\vec{r}^{\prime}\right) d \vec{r} d \vec{r}^{\prime}-2 \iint \rho_{N+1}(\vec{r}) \Theta\left(\vec{r}, \vec{r}^{\prime}\right) \rho_{N}\left(\vec{r}^{\prime}\right) d \vec{r} d \vec{r}^{\prime}, \text { and } \\
\eta_{f^{0} f^{0}}(\Theta)=\iint f^{0}(r) \Theta\left(r, r^{\prime}\right) f^{0}\left(r^{\prime}\right) d r d r^{\prime}=\frac{1}{4} \iint\left(\rho_{N+1}(r)-\rho_{N-1}(r)\right) \Theta\left(r, r^{\prime}\right)\left(\rho_{N+1}\left(r^{\prime}\right)-\rho_{N-1}\left(r^{\prime}\right)\right) d r d r^{\prime} \\
=\frac{1}{4}\left[\iint \rho_{N+1}(r) \Theta\left(r, r^{\prime}\right) \rho_{N+1}\left(r^{\prime}\right) d r^{\prime} d r^{\prime}+\iint \rho_{N-1}(r) \Theta\left(r, r^{\prime}\right) \rho_{N-1}\left(r^{\prime}\right) d r d r^{\prime}-2 \iint \rho_{N+1}(r) \Theta\left(r, r^{\prime}\right) \rho_{N-1}\left(r^{\prime}\right) d r d r^{\prime}\right] .
\end{gathered}
$$

Expressing Eqs. (20) to (22) as a function of the QMSMs defined above, we can write:

$$
\begin{gathered}
\eta_{f^{-} f^{-}}(\Theta)=Z_{\rho_{N} \rho_{N}}(\Theta)+Z_{\rho_{N-1} \rho_{N-1}}(\Theta)-2 Z_{\rho_{N} \rho_{N-1}}(\Theta), \\
\eta_{f^{+} f^{+}}(\Theta)=Z_{\rho_{N+1} \rho_{N+1}}(\Theta)+Z_{\rho_{N} \rho_{N}}(\Theta)-2 Z_{\rho_{N+1} \rho_{N}}(\Theta) \text {, and } \\
\eta_{f^{0} f^{0}}(\Theta)=\frac{1}{4}\left[Z_{\rho_{N+1} \rho_{N+1}}(\Theta)+Z_{\rho_{N-1} \rho_{N-1}}(\Theta)-2 Z_{\rho_{N+1} \rho_{N-1}}(\Theta)\right] .
\end{gathered}
$$

Thus, one can compute hardnesses from Eq. (9) with the hardness kernel approximations represented by Eqs. (14) and (16) by using Coulomb-like and overlap-like QMSMs, respectively, in Eqs. (23) to (25). 
In our previous work [40], we showed that the simplest and computationally cheapest model, $\eta\left(\vec{r}, \vec{r}^{\prime}\right) \cong \delta\left(\vec{r}-\vec{r}^{\prime}\right)$, affords the most reasonable hardness molecular ordering. We also found that the hybrid density functional B3LYP [46], second-order Møller Plesset (MP2) [47], and singles and doubles quadratic configuration interaction (QCSID) [48] methods yield qualitatively the same results, although the MP2 gives somewhat better results when compared to experimental hardnesses. Accordingly, we have used in this study the $\eta\left(\vec{r}, \vec{r}^{\prime}\right) \cong \delta\left(\vec{r}-\vec{r}^{\prime}\right)$ model for the hardness kernel and the MP2 methodology to compute hardnesses.

The Gaussian 98 program [49] has been used to perform correlated MP2 calculations of vertical ionization potential $(I)$ and electron affinities $(A)$, and molecular electron densities. The HOMO and LUMO orbital energies have been obtained at the HF level. The basis set used for all calculations has been the 6-31++G** [50]. Calculated $A$ and I are always vertical values (no change in nuclear positions) computed using the MP2/6$31++G^{* *}$ optimized geometry of the original system. Indeed, including electron correlation is quite important to compare chemical species with different number of electrons [51]. Thus, in the calculation of $I$ and $A$ values it is highly advisable to go beyond the HF method [22,52], the MP2 method being one of cheapest and more effective choices. Less relevant seems to be the effect of electron correlation in the Fukui functions [53].

All calculations have been done within the restricted formalism except for openshells systems that have been calculated using the unrestricted approach. The methodology employed for the calculations of the quantum molecular similarity measures has been same as in our previous work [40]. QMSMs have been obtained from the Gaussian 98 MP2 generalized densities [54] using the Messem [55] program developed in our group. 


\section{RESULTS AND DISCUSSION}

The methodology explained in the previous section has been applied to a different set of Lewis bases (anions) and Lewis acids (cations and neutral molecules). In this study, we will compare the results of overlap-like Fukui self-similarity measures (OFFS) (Eqs. (23) to (25) with $\left.\eta\left(\vec{r}, \vec{r}^{\prime}\right) \cong \delta\left(\vec{r}-\vec{r}^{\prime}\right)\right)$ with those obtained from the conventional hardness definition (Eqs. (3) and (4)).

It is worth noting that this study is qualitative, its main goal being to prove that OFFSs could be an excellent alternative to the traditional and operational forms of hardness for ordering molecules according to their hardness values. It is important to design new methods that give the correct ordering by hardness for a series of molecules. Indeed, application of the HSAB and the MHP principles only requires knowing whether the hardness of some species is greater or smaller than that of a certain system of reference. On the other hand, accurate theoretical values of hardness are also very relevant because in some cases (for instance in anions) their experimental determination is not trivial.

Tables 1 and 2 group some Lewis bases and acids as hard, borderline or soft according to Pearson [3]. This classification will be used to analyze the obtained results and to evaluate the efficiency of the different methodologies employed to calculate the hardness.

In this section, we will first analyze some anionic Lewis bases. Experimentally, it is very difficult to evaluate the hardness of these species since anionic Lewis bases carrying an extra electron are unstable. For this reason, it is not possible to measure their electron affinity and Eq. (3) cannot be applied to these species. In these systems, the absolute value of electron affinity can be larger than the ionization potential, the electron affinity becoming the more relevant component of the hardness as expected from the fact that much 
energy is required to force an electron on to systems that have already an excess of electrons. Secondly, we will study some cationic and neutral Lewis acids. Despite cations are less problematic than anions, they can also present some experimental problems; e.g. except for monoatomic cations, second ionization potentials cannot be usually measured.

\subsection{Lewis Bases}

Table 3 collects the MP2 hardness values of different anionic Lewis bases calculated with the operational expressions given by Eqs. (3) and (4) and with the alternative procedure that employs OFSS measures (Eqs. (23) to (25)).

TABLE 3 here

Due to different molecular polarizabilities and diverse electronegativities [56,57] of the central atoms is reasonable to expect the following relations among the several Lewis bases analyzed here:

$$
\begin{gathered}
\eta\left(\mathrm{F}^{-}\right)>\eta\left(\mathrm{Cl}^{-}\right)>\eta\left(\mathrm{Br}^{-}\right), \quad \eta\left(\mathrm{OH}^{-}\right)>\eta\left(\mathrm{SH}^{-}\right), \quad \eta\left(\mathrm{NH}_{2}^{-}\right)>\eta\left(\mathrm{PH}_{2}^{-}\right), \\
\eta\left(\mathrm{F}^{-}\right)>\eta\left(\mathrm{OH}^{-}\right)>\eta\left(\mathrm{NH}_{2}^{-}\right)>\eta\left(\mathrm{CH}_{3}^{-}\right), \quad \eta\left(\mathrm{NO}_{3}^{-}\right)>\eta\left(\mathrm{NO}_{2}^{-}\right), \\
\eta\left(\mathrm{Cl}^{-}\right)>\eta\left(\mathrm{SH}^{-}\right)>\eta\left(\mathrm{PH}_{2}^{-}\right)>\eta\left(\mathrm{SiH}_{3}^{-}\right), \text {and } \eta\left(\mathrm{CH}_{3}^{-}\right)>\eta\left(\mathrm{SiH}_{3}^{-}\right) .
\end{gathered}
$$

For instance, the $\mathrm{OH}^{-}$anion is harder than the $\mathrm{SH}^{-}$species because the oxygen atom attracts more its electrons than the sulfur atom $(\chi(\mathrm{O})>\chi(\mathrm{S}))$. As a consequence, the electronic cloud of the $\mathrm{SH}^{-}$species is more polarizable and it is more difficult to change the electronic configuration of $\mathrm{OH}^{-}$than that of $\mathrm{SH}^{-}$. Similar arguments can be provided to justify the rest of relationships.

Among the five methods used to calculate the hardness, the only method that affords the qualitative ordering predicted by Eq. (26) is the method based on electrophilic OFSS 
measures, $\eta_{f^{-} f^{-}}\left[\delta\left(\vec{r}-\vec{r}^{\prime}\right)\right]$. The method that uses radical OFSS measures, $\eta_{f^{0} f^{0}}\left[\delta\left(\vec{r}-\vec{r}^{\prime}\right)\right]$, erroneously predicts $\mathrm{SiH}_{3}{ }^{-}>\mathrm{CH}_{3}{ }^{-}$. On the other hand, the method based on the traditional hardness definition represented by Eq. (3), $\eta_{1}$, produces the same error and in addition incorrectly yields the relation $\mathrm{SiH}_{3}{ }^{-}>\mathrm{PH}_{2}{ }^{-}$. These two errors are also reproduced by the hardness calculated with Eq. (4), $\eta_{2}$, that additionally wrongly gives the same hardness for $\mathrm{PH}_{2}{ }^{-}$and $\mathrm{NH}_{2}{ }^{-}$.

The method based on the calculation of nucleophilic OFSS measures, $\eta_{f^{+} f^{+}}\left[\delta\left(\vec{r}-\vec{r}^{\prime}\right)\right]$, is the one that yields the worst results. This can be rationalized by taking into account that these molecules due their inherent basic character do not undergo nucleophilic attacks, and therefore the nucleophilic OFSS measures are inadequate to calculate the hardness in Lewis bases.

Alkyl groups [58] are usually regarded as electron-donating (+I) substituents. However, there are also many examples that the chemical behavior of the methyl group has been interpreted considering that alkyl groups are electron-withdrawing (-I) when compared to hydrogen [59]. This is the case of some anionic species such as $\mathrm{CH}_{3} \mathrm{O}^{-}$. In this anion, the alkyl group, instead of transferring charge to the central atom, is used to delocalize part of the electronic density of the central atom. In particular, calculations at the MP2/6-31++G** level of theory show that the oxygen atom decreases its negative Mulliken population by 0.326 electrons when going from the hydroxy to the methoxy anion, indicating that the methyl group in the methoxy anion acts as an electron acceptor. In such a case, the effect of the substitution of a hydrogen atom by an alkyl group generates a 
softer system that has fewer electrons in the central atom and a more polarizable electronic cloud. Based on these arguments, one could expect the following relations:

$$
\begin{gathered}
\eta\left(\mathrm{OH}^{-}\right)>\eta\left(\mathrm{CH}_{3} \mathrm{O}^{-}\right), \quad \eta\left(\mathrm{SH}^{-}\right)>\eta\left(\mathrm{CH}_{3} \mathrm{~S}^{-}\right), \quad \text { and } \\
\eta\left(\mathrm{NH}_{2}^{-}\right)>\eta\left(\mathrm{CH}_{3} \mathrm{NH}^{-}\right)>\eta\left(\left(\mathrm{CH}_{3}\right)_{2} \mathrm{~N}^{-}\right) \text {. }
\end{gathered}
$$

The first relation in Eq. (27) is fulfilled by $\eta_{1}, \quad \eta_{2}, \quad \eta_{f^{-} f^{-}}\left[\delta\left(\vec{r}-\vec{r}^{\prime}\right)\right]$, and $\eta_{f^{0} f^{0}}\left[\delta\left(\vec{r}-\vec{r}^{\prime}\right)\right]$, while the second is satisfied by $\eta_{1}, \eta_{2}$, and $\eta_{f^{0} f^{0}}\left[\delta\left(\vec{r}-\vec{r}^{\prime}\right)\right]$, but surprisingly not by $\eta_{f^{-} f^{-}}\left[\delta\left(\vec{r}-\vec{r}^{\prime}\right)\right]$, although according to $\eta_{f^{-} f^{-}}\left[\delta\left(\vec{r}-\vec{r}^{\prime}\right)\right]$ the hardnesses of $\mathrm{SH}^{-}$and $\mathrm{CH}_{3} \mathrm{~S}^{-}$are quite similar. Finally, all methods fail in predicting the last relation.

The classification of the molecules given by Eqs. (26) and (27) is not followed precisely by any of the theoretical methods employed. Probably even more interesting than to analyze the exact position of each molecule given by the different methods is to discuss the general trends. To this end, Table 4 contains the ordering by hardness of the different molecules for the different methods employed. Dark grey cells in this Table represent hard systems according to Table 1, while grey and white cells represent borderline and soft species, respectively.

\section{TABLE 4 here}

Results in Table 4 show that the method based on $\eta_{f^{-} f^{-}}\left[\delta\left(\vec{r}-\vec{r}^{\prime}\right)\right]$ measures is the only one that exactly reproduces the classification of Table 1 . Furthermore, $H^{-}$is the softest molecule among the studied set and the only method that places it in its correct position is the method based on electrophilic OFSS measures, $\eta_{f^{-} f^{-}}\left[\delta\left(\vec{r}-\vec{r}^{\prime}\right)\right]$.

The $\eta_{f^{0} f^{0}}\left[\delta\left(\vec{r}-\vec{r}^{\prime}\right)\right]$ also gives generally correct results, although it overestimates the hardness of $\mathrm{NO}_{2}{ }^{-}$. Finally, it is clearly seen in Table 4 that $\eta_{1}$ and $\eta_{2}$ erroneously 
classify several systems. For instance, the $\mathrm{CH}_{3} \mathrm{NH}^{-}$and $\left(\mathrm{CH}_{3}\right)_{2} \mathrm{~N}^{-}$species, which belong to the group of hard molecules, are considered as soft molecules, whereas a soft molecule such as $\mathrm{H}^{-}$shows the same hardness as hard molecules like $\mathrm{OH}^{-}$and $\mathrm{Cl}^{-}$.

\subsection{Lewis Acids}

Table 5 contains the hardness of the different Lewis acids calculated using the conventional expressions given by Eqs. (3) and (4) and the OFSS measures of Eqs. (23) to (25). Based on the definition of hardness and the qualitative ordering of Table 2, we can expect the following relations among the several Lewis acids analyzed here,

$$
\begin{gathered}
\eta\left(\mathrm{Li}^{+}\right)>\eta\left(\mathrm{Na}^{+}\right)>\eta\left(\mathrm{K}^{+}\right), \quad \eta\left(\mathrm{Be}^{2+}\right)>\eta\left(\mathrm{Mg}^{2+}\right)>\eta\left(\mathrm{Ca}^{2+}\right), \eta\left(\mathrm{Al}^{3+}\right)>\eta\left(\mathrm{Ga}^{3+}\right) \\
\eta\left(\mathrm{Al}^{3+}\right)>\eta\left(\mathrm{Mg}^{2+}\right)>\eta\left(\mathrm{Na}^{+}\right), \quad \text { and } \eta\left(\mathrm{F}_{2}\right)>\eta\left(\mathrm{Cl}_{2}\right)>\eta\left(\mathrm{Br}_{2}\right) .
\end{gathered}
$$

These relations are fulfilled by all theoretical methods analyzed, except for the nucleophilic

OFSS measures, $\eta_{f^{+} f^{+}}\left[\delta\left(\vec{r}-\vec{r}^{\prime}\right)\right]$, that predicts $\mathrm{Ga}^{3+}$ to be harder than $\mathrm{Al}^{3+}$. On the same grounds one can also predict the following relations,

$$
\begin{gathered}
\eta\left(\mathrm{Ga}^{3+}\right)>\eta\left(\mathrm{Ca}^{2+}\right)>\eta\left(\mathrm{K}^{+}\right), \quad \eta\left(\mathrm{BF}_{3}\right)>\eta\left(\mathrm{BCl}_{3}\right)>\eta\left(\mathrm{BBr}_{3}\right), \\
\eta\left(\mathrm{AlF}_{3}\right)>\eta\left(\mathrm{AlCl}_{3}\right)>\eta\left(\mathrm{AlBr}_{3}\right), \text { and } \eta\left(\mathrm{SO}_{3}\right)>\eta\left(\mathrm{SO}_{2}\right) .
\end{gathered}
$$

The first relation in Eq. (29) is correctly predicted only by the OFSS measures, while $\eta_{1}$ and $\eta_{2}$ hardness values are the unique methods that properly place the systems according the second and third relations of Eq. (29). It is worth noting that despite the fact that classification in Table 2 predicts $\mathrm{SO}_{3}$ to be harder than $\mathrm{SO}_{2}$, experimentally the opposite trend is found, although the difference of experimental hardness between $\mathrm{SO}_{2}$ and 
$\mathrm{SO}_{3}$ is only $0.2 \mathrm{eV}$. All theoretical methods in Table 5 predict $\eta\left(\mathrm{SO}_{3}\right)>\eta\left(\mathrm{SO}_{2}\right)$, except the radical OFSS measures, $\eta_{f^{0} f^{0}}\left[\delta\left(\vec{r}-\vec{r}^{\prime}\right)\right]$.

TABLE 5 here

The molecular ordering by hardness obtained with the $\eta_{f^{+} f^{+}}\left[\delta\left(\vec{r}-\vec{r}^{\prime}\right)\right]$ measures of Lewis acids is better when compared to the ordering obtained using the same measures in the Lewis basis of the preceding section. However, the results derived from nucleophilic OFSS measures are still worse than those based on the use of radical and electrophilic OFSS measures. The failure of $\eta_{f^{+} f^{+}}\left[\delta\left(\vec{r}-\vec{r}^{\prime}\right)\right]$ is somewhat unexpected if one considers that these molecules due their intrinsic acid character undergo nucleophilic attacks, and therefore the nucleophilic OFSS measures should be adequate to calculate the hardness in Lewis acids. However, it is also true that being the hardness a measure of the resistance of a chemical species to change its electronic configuration, one should include in the calculation the effects of both adding one electron to the system and removing one electron from it. These two effects are fundamental to correctly define the curvature of the $E$ vs. $N$ function, i.e., the hardness (Eq. (1)). In this sense, being $f^{0}(\vec{r})$ the only Fukui function that incorporates these two effects, the use of $\eta_{f^{0} f^{0}}\left[\delta\left(\vec{r}-\vec{r}^{\prime}\right)\right]$ to order the systems by hardness seems to be more reasonable than the use of either $\eta_{f^{+} f^{+}}\left[\delta\left(\vec{r}-\vec{r}^{\prime}\right)\right]$ or $\eta_{f^{-} f^{-}}\left[\delta\left(\vec{r}-\vec{r}^{\prime}\right)\right]$. This fact was already pointed out by Gázquez who showed that $I$ could be written as [60]:

$$
I=-\mu^{o}+\frac{1}{2} \iint f^{-}(\vec{r}) \eta\left(\vec{r}, \vec{r}^{\prime}\right) f^{-}\left(\vec{r}^{\prime}\right) d \vec{r} d \vec{r}^{\prime},
$$

and $A$ as:

$$
A=-\mu^{o}+\frac{1}{2} \iint f^{+}(\vec{r}) \eta\left(\vec{r}, \vec{r}^{\prime}\right) f^{+}\left(\vec{r}^{\prime}\right) d \vec{r} d \vec{r}^{\prime},
$$


and that according to Eq. (5):

$$
\eta=I-A=\iint f^{o}(\vec{r}) \eta\left(\vec{r}, \vec{r}^{\prime}\right) f^{o}\left(\vec{r}^{\prime}\right) d \vec{r} d \vec{r}^{\prime}
$$

A linear regression using the calculated hardness and the experimental values as the y and x components, respectively, shows that $\eta_{1}$ and $\eta_{2}$ produce better results $\left(\mathrm{r}^{2}=0.98\right)$ than the OFSS measures $\left(\eta_{f^{0} f^{0}}\left[\delta\left(\vec{r}-\vec{r}^{\prime}\right)\right]\right.$ and $\eta_{f^{-} f^{-}}\left[\delta\left(\vec{r}-\vec{r}^{\prime}\right)\right], \mathrm{r}^{2}=0.93$ and $\mathrm{r}^{2}=0.94$, respectively). The improvement of the values obtained with $\eta_{1}$ and $\eta_{2}$ with respect to the results of the preceding section and those obtained in our previous work [40], are related to the fact that for Lewis acids the main component of the hardness computed with Eq. (3) is the ionization potential, while in Lewis bases the electron affinity is quite large and it can be even more important than the ionization potential. So $\eta_{1}$ and $\eta_{2}$ give good results in Lewis acids because the conventional $a b$ initio and DFT methods provide reasonable ionization potentials, as shown by several authors [61]. More difficult is the theoretical study of the electron affinities [62]. The results obtained using OFSS measures in Lewis acids are not as impressive as those presented in the previous section and in our previous work for Lewis bases, although they give still excellent results and are a good alternative for systems having experimental or theoretical $I$ or $A$ that are difficult to determine.

\section{CONCLUSIONS}

In this paper, we have tested an approximate hardness kernel, $\eta\left(\vec{r}, \vec{r}^{\prime}\right) \cong \delta\left(\vec{r}-\vec{r}^{\prime}\right)$, for the evaluation of the global hardness in a series of anionic Lewis bases and neutral and cationic Lewis acids. Since the most common operative expressions to calculate the hardness of a system are quite approximate, it is very important to explore new methods to calculate hardnesses. In the case of Lewis bases, the intuitive order of hardness supported 
by polarizability and electronegativity arguments and given by Eqs. (26) and (27) is better reproduced by the methods based on radical and electrophilic OFSS measures than by methods based on the common operational expressions (Eqs. (3) and (4)). For Lewis acids the molecular order by hardness is in most cases correctly reproduced by $\eta_{f^{0} f^{0}}\left[\delta\left(\vec{r}-\vec{r}^{\prime}\right)\right]$, $\eta_{f^{-} f^{-}}\left[\delta\left(\vec{r}-\vec{r}^{\prime}\right)\right]$, and by Eqs. (3) and (4). Despite both radical and electrophilic OFSS measures provide excellent molecular classifications by hardness for Lewis acids and bases, we recommend the use of radical OFSS measures since $f^{0}(\vec{r})$ is the only Fukui function that includes in some way the effects of adding electron charge to the system and removing charge from it.

As a whole, we have shown here that the calculation of hardness for both acids and bases through the use of radical OFSS measures is a very good alternative to the operational expressions, especially if one wants to know whether a system is harder or softer than a molecule of reference, as required by the MHP and HSAB principles.

\section{ACKNOWLEDGMENTS}

We are grateful to Professor Juvencio Robles for helpful comments. Support for this work from the Spanish Ministerio de Ciencia y Tecnología (projects No. BQU2002-04112C02-02 and BQU2002-03334), from the DURSI (Generalitat de Catalunya) (project 2001SGR-00290), and the use of the computational facilities of the Catalonia Supercomputer Center (CESCA) are gratefully acknowledged. M. T.-S. is financed through CIRIT Project No. FI/01-000699 from the Generalitat de Catalunya. M. S. thanks the DURSI for financial support through the Distinguished University Research Promotion, 2001. 


\section{REFERENCES}

1 R.G. Parr, W. Yang, Density-Functional Theory of Atoms and Molecules, Oxford University Press, New York, 1989.

$2 \quad$ R.G. Pearson, J. Org. Chem. 54 (1989) 1423.

3 R.G. Pearson, Chemical Hardness: Applications from Molecules to Solids, WileyVCH, Weinheim, 1997.

$4 \quad$ R.G. Parr, Z. Zhou, Acc. Chem. Res. 26 (1993) 256.

5 (a) H. Chermette, J. Comput. Chem. 20 (1999) 129. (b) P. Geerlings, F. De Proft, W. Langenaeker, Chem. Rev. 103 (2003) 1793.

6 R.G. Parr, R.G. Pearson, J. Am. Chem. Soc. 105 (1983) 7512.

7 (a) P.K. Chattaraj, H. Lee, R.G. Parr, J. Am. Chem. Soc. 113 (1991) 1855. (b) Y. Li, J.N.S. Evans, J. Am. Chem. Soc. 117 (1995) 7756.

8 (a) R.G. Pearson, J. Chem. Educ. 64 (1987) 561. (b) R. G. Pearson, J. Chem. Educ. 76 (1999) 267.

9 M. Torrent-Sucarrat, J.M. Luis, M. Duran, M. Solà, J. Am. Chem. Soc. 123 (2001) 7951.

10 S.K. Ghosh, M. Berkowitz, J. Chem. Phys. 83 (1985) 2976.

11 (a) M. Berkowitz, S.K. Ghosh, R.G. Parr, J. Am. Chem. Soc. 107 (1985) 6811. (b) M. Berkowitz, R.G. Parr, J. Chem. Phys. 88 (1988) 2554.

12 R.G. Parr, W. Yang, J. Am. Chem. Soc. 106 (1984) 4049.

13 See for instance: (a) W. Langenaeker, K. Demel, P. Geerlings, J. Mol. Struct. (Theochem) 234 (1991) 329. (b) F. De Proft, W. Langenaeker, P. Geerlings, J. Phys. Chem. 97 (1993) 1826. (c) W. Langenaeker, F. De Proft, P. Geerlings, J. Phys. Chem. 99 (1995) 6424. (d) S. Krishnamurti, R.K. Koy, R. Vetrivel, S. Iwata, S. Pal, J. Phys. Chem. 101 (1997) 7253. (e) R.K. Koy, S. Krishnamurti, P. Geerlings, S. Pal, J. Phys. Chem. 102 (1998) 3746. (f) M. de L. Romero, F. Méndez, J. Phys. Chem. A. 107 (2003) 5874.

14 R.G. Parr, R.A. Donnelly, M. Levy, W.E. Palke, J. Chem. Phys. 68 (1978) 3801.

15 R.P. Iczkowski, J.L. Margrave, J. Am. Chem. Soc. 83 (1961) 3547.

16 R.G. Pearson, J. Am. Chem. Soc. 107 (1985) 6801. 
17 R.G. Parr, Z. Zhou, Acc. Chem. Res. 26 (1993) 256.

18 R.G. Parr, P.K. Chattaraj, J. Am. Chem. Soc. 131 (1991) 1854.

19 P.J. Politzer, J. Chem. Phys. 86 (1987) 1072.

20 T. Koopmans, Physica 1 (1934) 104.

21 (a) G. Schulz, J. Phys. Rev. 5 (1972) 1672. (b) K.D. Jordan, P.D. Burrow, Chem. Rev. 87 (1987) 557.

22 F. De Proft, P. Geerlings, J. Chem. Phys. 106 (1997) 3270.

23 W. Kohn, A.D. Becke, R.G. Parr, J. Phys Chem. 100 (1996) 12974.

24 J.P. Perdew, R.G. Parr, M. Levy, J.L. Balduz, Phys. Rev. Lett. 49 (1982) 1691.

25 T.T. Nguyen-Dang, R.F.W. Bader, H. Essén, Int. J. Quantum Chem. 22 (1982) 1049.

26 (a) L. Komorowski, Chem. Phys. Lett. 103 (1983) 201. (b) R. Balawender, L. Komorowski, J. Chem. Phys. 109 (1998) 5203. (c) T. Mineva, E. Sicilia, N. Russo, J. Am. Chem. Soc. 120 (1998) 9053. (d) M.V. Putz, N. Russo, E. Sicilia, J. Comput. Chem. 25 (2004) 994.

27 W. Yang, R.G. Parr, R. Pucci, J. Chem. Phys. 81 (1984) 2862.

28 (a) K. Fukui, T. Yonezawa, H. Shingu, J. Chem. Phys. 20 (1952) 722. (b) K. Fukui, T. Yonezawa, C. Nagata, H. Shingu, J. Chem. Phys. 22 (1954) 1433.

29 S.K. Ghosh, Chem. Phys. Lett. 172 (1990) 77.

30 P.K. Chattaraj, A. Cedillo, R.G. Parr, J. Chem. Phys. 103 (1995) 7645.

31 (a) J. Garza, J. Robles, Phys. Rev. A 47 (1993) 2680. (b) P. Fuentealba, J. Chem. Phys. 103 (1995) 6571. (c) P.K. Chattaraj, A. Cedillo, R.G. Parr, J. Chem. Phys. 103 (1995) 10621.

32 P. Fuentealba, J. Chem. Phys. 103 (1995) 6571.

33 (a) L.H. Thomas, Proc. Camb. Philos. Soc. 23 (1927) 542. (b) E. Fermi, Z. Phys. 48 (1928) 73.

34 P.M.A. Dirac, Proc. Camb. Philos. Soc. 26 (1930) 376.

35 G.H. Liu, J. Chem. Phys. 106 (1997) 165.

36 J. Garza, J. Robles, Int. J. Quantum Chem. 49 (1994) 159.

37 T. K. Ghanty, S. K. Ghosh, J. Phys. Chem. 98 (1994) 9197.

38 P. Senet, Chem. Phys. Lett. 275 (1997) 527.

39 S. Liu, F. De Proft, R.G. Parr, J. Phys. Chem. A 101 (1997) 6991. 
40 M. Torrent-Sucarrat, M. Duran, M. Solà, J. Phys. Chem. A 106 (2002) 4632.

41 See for instance: (a) M. Solà, J. Mestres, R. Carbó, M. Duran, J. Am. Chem. Soc. 116 (1994) 5909. (b) M. Solà, J. Mestres, M. Duran, R. Carbó, J. Chem. Inf. Comput. Sci. 34 (1994) 1047. (c) M. Solà, J. Mestres, R. Carbó, M. Duran, J. Chem. Phys. 104 (1996) 636. (d) J. Mestres, M. Solà, R. Carbó, F.J. Luque, M. Orozco, J. Phys. Chem. 100 (1996) 606. (e) J. Poater, M. Duran, M. Solà, J. Comput. Chem. 22 (2001) 1666.

(a) D. Robert, L. Amat, R. Carbó-Dorca, J. Chem. Inf. Comput. Sci. 39 (1999) 333. (b) X. Gironés, A. Gallegos, R. Carbó-Dorca, J. Chem. Inf. Comput. Sci. 40 (2000) 1400. (c) A. Gallegos, D. Robert, X. Gironés, R. Carbó-Dorca, J. Comput.-Aided Mol. Desing 15 (2001) 67. (d) A. Gallegos, L. Amat, R. Carbó-Dorca, T.W. Schultz, M. Cronin, J. Chem. Inf. Comp. Sci. 43 (2003) 1166. (e) A. Gallegos, R. Carbó-Dorca, R. Ponec, K. Waisser, Int. J. Pharm. 269 (2004) 51.

43 R. Carbó, M. Arnau, L. Leyda, Int. J. Quantum Chem. 17 (1980) 1185.

44 E. Besalú, R. Carbó, J. Mestres, M. Solà, Top. Curr. Chem. 173 (1995) 31.

45 M. Solà, J. Mestres, J.M. Oliva, M. Duran, R. Carbó, Int. J. Quantum Chem. 58 (1996) 361.

46 (a) C. Lee, W. Yang, R.G. Parr, Phys. Rev. B 37 (1988) 785. (b) A.D. Becke, J. Chem. Phys. 98 (1993) 5648. (c) P.J. Stephens, F.J. Devlin, C.F. Chabalowski, M.J. Frisch, J. Phys. Chem. 98 (1994) 11623.

47 C. Møller, M.S. Plesset, Phys. Rev. 46 (1934) 618.

48 J.A. Pople, M. Head-Gordon, K. Raghavachari, J. Chem. Phys. 87 (1987) 5968.

49 M.J. Frisch, G.W. Trucks, H.B. Schlegel, G. Scuseria, M.A. Robb, J.R. Cheeseman, V.G. Zakrzewski, J.A. Montgomery, R.E. Stratmann, J.C. Burant, S. Dapprich, J.M. Millam, A.D. Daniels, K.N. Kudin, M.C. Strain, O. Farkas, J. Tomasi, V. Barone, M. Cossi, R. Cammi, B. Mennucci, C. Pomelli, C. Adamo, S. Clifford, J. Ochterski, G.A. Petersson, P.Y. Ayala, Q. Cui, K. Morokuma, D.K. Malick, A.D. Rabuck, K. Raghavachari, J.B. Foresman, J. Cioslowski, J.V. Ortiz, B.B. Stefanov, G. Liu, A. Liashenko, P. Piskorz, I. Komaromi, R. Gomperts, R.L. Martin, D.J. Fox, T. Keith, M. Al-Laham, C. Peng, A. Nanayakkara, C. Gonzalez, M. Challacombe, P.M.W. Gill, B.G. Johnson, W. Chen, M.W. Wong, J.L. Andres, M. Head-Gordon, E.S. Replogle, J.A. Pople, J. A. Gaussian 98; Gaussian Inc., Pittsburgh, PA, GAUSSIAN 98, Revision A.6, 1998. 
50 W.J. Hehre, L. Radom, P.v.R. Schleyer, J.A. Pople, Ab Initio Molecular Orbital Theory, Wiley, New York, 1986.

51 P. Čársky, M.Urban, Ab initio Calculations (Lecture Notes in Chemistry 16), Springer Verlag, Berlin, 1980.

52 F. De Proft, W. Langaneaker, P. Geerlings, J. Phys. Chem. 97 (1993) 1826.

53 W. Langenaeker, F. De Proft, P. Geerlings, J. Mol. Struct. (Theochem) 362 (1996) 175.

54 N.C. Handy, H.F. Schaefer III, J. Chem. Phys. 81 (1984) 5031.

55 (a) J. Mestres, M. Solà, E. Besalú, M. Duran, R. Carbó, MESSEM, Girona, CAT, 1993. (b) E. Besalú, R. Carbó, M. Duran, J. Mestres, M. Solà, Methods and Techniques in Computational Chemistry (METTEC-95), C. Clementi, G. Corongiu, (Eds.), STEF: Cagliari, 1995, pp. 491-508.

56 L. Pauling, J. Am. Chem. Soc. 54 (1932) 3570.

57 L. Pauling, The Nature of the Chemical Bond, Cornell University Press, New York, 1960.

58 J. March, Advanced Organic Chemistry: Reactions, Mechanism and Structure, Wiley-Interscience Publication, New York, 1992.

59 a) P.v.R. Schleyer, C.W. Woodworth, J. Am. Chem. Soc. 90 (1968) 6528. b) G.H. Wahl, M.R. Peterson, J. Am. Chem. Soc. 92 (1970) 7238.

60 J. L. Gázquez, Structure and Bonding, 80 (1993) 27.

61 (a) U. Salzner, J.B. Lagowski, P.G. Pickup, R.A. Poirier, J. Comput. Chem. 18 (1997) 1943. (b) P. Politzer, F. Abu-Awwad, Theor. Chem. Acc. 99 (1998) 83. (c) G. Contini, V. Dicastro, S. Stranges, R. Richter, M. Alagia, J. Phys. Chem. A 104 (2000) 9675. (d) F.W. Chen, E.R. Davidson, J. Phys. Chem. A. 105 (2001) 4558.

62 (a) F. De Proft, P. Geerlings, J. Chem. Phys. 106 (1997) 3270. (b) N. Russo, M. Toscano, A. Grand, J. Comput. Chem. 21 (2000) 1243. (c) J.C. Rienstra-Kiracofe, G.S. Tschumper, H.F. Schaefer III, S. Nandi, G.B. Ellison, Chem. Rev. 102 (2002) 231. (d) C.-G. Zhan, J.A. Nichols, D.A. Dixon, J. Phys. Chem. A 107 (2003) 4184.

63 R.G. Pearson, Inorg. Chem. 27 (1998) 734.

64 D. R. Lide, Handbook of Chemistry and Physics 72nd Edition, CRC Press, INC, 1991. 
Table 1

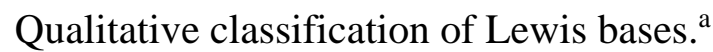

\begin{tabular}{ccc}
\hline Hard & Borderline & Soft \\
\hline $\mathrm{F}^{-}, \mathrm{H}_{2} \mathrm{O}, \mathrm{OH}^{-}, \mathrm{ROH}, \mathrm{RO}^{-}$, & $\mathrm{C}_{6} \mathrm{H}_{5} \mathrm{NH}_{2}, \mathrm{C}_{5} \mathrm{H}_{5} \mathrm{~N}$, & $\mathrm{H}_{2} \mathrm{~S}, \mathrm{HS}^{-}, \mathrm{RSH}, \mathrm{RS}^{-}$, \\
$\mathrm{R}_{2} \mathrm{O}, \mathrm{NH}_{3}, \mathrm{NH}_{2}^{-}, \mathrm{RNH}_{2}$, & $\mathrm{Br}^{-}, \mathrm{NO}_{2}{ }^{-}$ & $\mathrm{R}_{2} \mathrm{~S}, \mathrm{PH}_{2}{ }^{-}, \mathrm{CH}_{3}{ }^{-}$, \\
$\mathrm{RNH}^{-}, \mathrm{R}_{2} \mathrm{~N}^{-}, \mathrm{Cl}^{-}, \mathrm{NO}_{3}{ }^{-}$ & & $\mathrm{SiH}_{3}^{-}, \mathrm{H}^{-}, \mathrm{I}^{-}$ \\
\hline
\end{tabular}

${ }^{\mathrm{a}}$ From Ref. [3]. 
Table 2

Qualitative classification of Lewis acids. ${ }^{\text {a }}$

\begin{tabular}{ccc}
\hline Hard & Borderline & Soft \\
\hline $\mathrm{Li}^{+}, \mathrm{Na}^{+}, \mathrm{K}^{+}, \mathrm{Be}^{2+}, \mathrm{Mg}^{2+}$, & & \\
$\mathrm{Ca}^{2+}, \mathrm{Al}^{3+}, \mathrm{Ga}^{3+}, \mathrm{Fe}^{3+}, \mathrm{BF}_{3}$, & $\mathrm{Fe}^{2+}, \mathrm{SO}_{2}, \mathrm{Ni}^{2+}$, & $\mathrm{Au}^{+}, \mathrm{Pd}^{2+}, \mathrm{Pt}^{2+}$, \\
$\mathrm{BCl}_{3}, \mathrm{~B}(\mathrm{OR})_{3}, \mathrm{SO}_{3}, \mathrm{CO}_{2}, \mathrm{~F}_{2}$ & $\mathrm{Cu}^{2+}, \mathrm{Zn}^{2+}, \mathrm{Pb}^{2+}$ & $\mathrm{Cu}^{+}, \mathrm{Ag}^{+}, \mathrm{Br}_{2}$ \\
& & \\
\hline
\end{tabular}

${ }^{\mathrm{a}}$ From Ref. [3]. 
Table 3

Calculated hardness for the anionic Lewis bases studied. $\eta_{1}$ is obtained using Eq. (3), $\eta_{2}$ is calculated from Eq. (4), while $\eta_{f^{-} f^{-}}\left[\delta\left(r-r^{\prime}\right)\right], \eta_{f^{+} f^{+}}\left[\delta\left(\vec{r}-\vec{r}^{\prime}\right)\right]$, and $\eta_{f^{0} f^{0}}\left[\delta\left(\vec{r}-\vec{r}^{\prime}\right)\right]$ values are derived from Eqs. (23) to (25), respectively.

\begin{tabular}{|c|c|c|c|c|c|}
\hline Molecule & $\eta_{1}{ }^{\mathrm{a}}$ & $\eta_{2}{ }^{\mathrm{a}}$ & $\eta_{f^{-} f^{-}}\left[\delta\left(\vec{r}-\vec{r}^{\prime}\right)\right]^{\mathrm{b}}$ & $\eta_{f^{+} f^{+}}\left[\delta\left(\vec{r}-\vec{r}^{\prime}\right)\right]^{\mathrm{b}}$ & $\eta_{f^{0} f^{0}}\left[\delta\left(\vec{r}-\vec{r}^{\prime}\right)\right]^{\mathrm{b}}$ \\
\hline $\mathrm{F}^{-}$ & 19.3 & 17.1 & 0.07284 & 0.00541 & 0.01959 \\
\hline $\mathrm{Cl}^{-}$ & 12.3 & 11.0 & 0.01675 & 0.00133 & 0.00447 \\
\hline $\mathrm{Br}^{-}$ & 10.6 & 9.7 & 0.01092 & 0.00090 & 0.00287 \\
\hline $\mathrm{OH}^{-}$ & 8.9 & 7.5 & 0.03742 & 0.00109 & 0.00917 \\
\hline $\mathrm{CH}_{3} \mathrm{O}^{-}$ & 7.5 & 6.2 & 0.03559 & 0.00053 & 0.00881 \\
\hline $\mathrm{SH}^{-}$ & 7.9 & 7.0 & 0.00996 & 0.00130 & 0.00258 \\
\hline $\mathrm{CH}_{3} \mathrm{~S}^{-}$ & 6.7 & 5.7 & 0.01045 & 0.00063 & 0.00250 \\
\hline $\mathrm{NH}_{2}{ }^{-}$ & 6.8 & 5.8 & 0.01553 & 0.00068 & 0.00378 \\
\hline $\mathrm{CH}_{3} \mathrm{NH}^{-}$ & 5.7 & 4.7 & 0.01739 & 0.00057 & 0.00422 \\
\hline$\left(\mathrm{CH}_{3}\right)_{2} \mathrm{~N}^{-}$ & 5.8 & 4.7 & 0.01490 & 0.00040 & 0.00333 \\
\hline $\mathrm{PH}_{2}^{-}$ & 6.6 & 5.8 & 0.00474 & 0.00076 & 0.00114 \\
\hline $\mathrm{NO}_{3}{ }^{-}$ & 13.9 & 12.4 & 0.04771 & 0.01297 & 0.01269 \\
\hline $\mathrm{NO}_{2}{ }^{-}$ & 12.8 & 10.6 & 0.01454 & 0.01770 & 0.00516 \\
\hline $\mathrm{CH}_{3}{ }^{-}$ & 5.6 & 4.9 & 0.00594 & 0.00560 & 0.00068 \\
\hline $\mathrm{SiH}_{3}{ }^{-}$ & 6.9 & 6.2 & 0.00427 & 0.00055 & 0.00100 \\
\hline $\mathrm{H}^{-}$ & 10.3 & 8.6 & 0.00281 & 0.00116 & 0.00112 \\
\hline
\end{tabular}

a units are $\mathrm{eV}$.

b units are atomic units. 
Table 4

Arrangement of the different Lewis bases according to the calculated hardnesses in Table 3 for the different methods studied. The hardness decreases in going down through a column.

The cells in dark grey correspond to hard molecules according to Table 1, while those in light grey or white represent borderline and soft molecules, respectively.

\begin{tabular}{|c|c|c|c|c|}
\hline$\eta_{1}$ & $\eta_{2}$ & $\eta_{f^{-} f^{-}}\left[\delta\left(\vec{r}-\vec{r}^{\prime}\right)\right]$ & $\eta_{f^{+} f^{+}}\left[\delta\left(\vec{r}-\vec{r}^{\prime}\right)\right]$ & $\eta_{f^{0} f^{0}}\left[\delta\left(\vec{r}-\vec{r}^{\prime}\right)\right]$ \\
\hline $\mathrm{F}^{-}$ & $\mathrm{F}^{-}$ & $\mathrm{F}^{-}$ & $\mathrm{NO}_{2}^{-}$ & $\mathrm{F}^{-}$ \\
\hline $\mathrm{NO}_{3}^{-}$ & $\mathrm{NO}_{3}^{-}$ & $\mathrm{NO}_{3}^{-}$ & $\mathrm{NO}_{3}^{-}$ & $\mathrm{NO}_{3}^{-}$ \\
\hline $\mathrm{NO}_{2}^{-}$ & $\mathrm{Cl}^{-}$ & $\mathrm{OH}^{-}$ & $\mathrm{CH}_{3}{ }^{-}$ & $\mathrm{OH}^{-}$ \\
\hline $\mathrm{Cl}^{-}$ & $\mathrm{NO}_{2}^{-}$ & $\mathrm{CH}_{3} \mathrm{O}^{-}$ & $\mathrm{F}^{-}$ & $\mathrm{CH}_{3} \mathrm{O}^{-}$ \\
\hline $\mathrm{Br}^{-}$ & $\mathrm{Br}^{-}$ & $\mathrm{CH}_{3} \mathrm{NH}^{-}$ & $\mathrm{Cl}^{-}$ & $\mathrm{NO}_{2}^{-}$ \\
\hline $\mathrm{H}^{-}$ & $\mathrm{H}^{-}$ & $\mathrm{Cl}^{-}$ & $\mathrm{SH}^{-}$ & $\mathrm{Cl}^{-}$ \\
\hline $\mathrm{OH}^{-}$ & $\mathrm{OH}^{-}$ & $\mathrm{NH}_{2}^{-}$ & $\mathrm{H}^{-}$ & $\mathrm{CH}_{3} \mathrm{NH}^{-}$ \\
\hline $\mathrm{SH}^{-}$ & $\mathrm{SH}^{-}$ & $\left(\mathrm{CH}_{3}\right)_{2} \mathrm{~N}^{-}$ & $\mathrm{OH}^{-}$ & $\mathrm{NH}_{2}^{-}$ \\
\hline $\mathrm{CH}_{3} \mathrm{O}^{-}$ & $\mathrm{SiH}_{3}^{-}$ & $\mathrm{NO}_{2}^{-}$ & $\mathrm{Br}^{-}$ & $\left(\mathrm{CH}_{3}\right)_{2} \mathrm{~N}^{-}$ \\
\hline $\mathrm{SiH}_{3}^{-}$ & $\mathrm{CH}_{3} \mathrm{O}^{-}$ & $\mathrm{Br}^{-}$ & $\mathrm{PH}_{2}^{-}$ & $\mathrm{Br}^{-}$ \\
\hline $\mathrm{NH}_{2}^{-}$ & $\mathrm{PH}_{2}^{-}$ & $\mathrm{CH}_{3} \mathrm{~S}^{-}$ & $\mathrm{NH}_{2}^{-}$ & $\mathrm{SH}^{-}$ \\
\hline $\mathrm{CH}_{3} \mathrm{~S}^{-}$ & $\mathrm{NH}_{2}^{-}$ & $\mathrm{SH}^{-}$ & $\mathrm{CH}_{3} \mathrm{~S}^{-}$ & $\mathrm{CH}_{3} \mathrm{~S}^{-}$ \\
\hline $\mathrm{PH}_{2}^{-}$ & $\mathrm{CH}_{3} \mathrm{~S}^{-}$ & $\mathrm{CH}_{3}{ }^{-}$ & $\mathrm{CH}_{3} \mathrm{NH}^{-}$ & $\mathrm{PH}_{2}^{-}$ \\
\hline$\left(\mathrm{CH}_{3}\right)_{2} \mathrm{~N}^{-}$ & $\mathrm{CH}_{3}{ }^{-}$ & $\mathrm{PH}_{2}^{-}$ & $\mathrm{SiH}_{3}^{-}$ & $\mathrm{H}^{-}$ \\
\hline $\mathrm{CH}_{3} \mathrm{NH}^{-}$ & $\left(\mathrm{CH}_{3}\right)_{2} \mathrm{~N}^{-}$ & $\mathrm{SiH}_{3}^{-}$ & $\mathrm{CH}_{3} \mathrm{O}^{-}$ & $\mathrm{SiH}_{3}^{-}$ \\
\hline $\mathrm{CH}_{3}{ }^{-}$ & $\mathrm{CH}_{3} \mathrm{NH}^{-}$ & $\mathrm{H}^{-}$ & $\left(\mathrm{CH}_{3}\right)_{2} \mathrm{~N}^{-}$ & $\mathrm{CH}_{3}{ }^{-}$ \\
\hline
\end{tabular}


Table 5

Calculated harness for the neutral and cations Lewis acids studied, $\eta_{1}$ is obtained using Eq.

(3), $\eta_{2}$ is calculated from Eq. (4), while $\eta_{f^{-} f^{-}}\left[\delta\left(\vec{r}-\vec{r}^{\prime}\right)\right], \eta_{f^{+} f^{+}}\left[\delta\left(\vec{r}-\vec{r}^{\prime}\right)\right]$, and $\eta_{f^{0} f^{0}}\left[\delta\left(\vec{r}-\vec{r}^{\prime}\right)\right]$ values are derived from Eqs. (23) to (25), respectively.

\begin{tabular}{|c|c|c|c|c|c|c|}
\hline Molecule & $\eta_{1}{ }^{\mathrm{a}}$ & $\eta_{2}^{\mathrm{a}}$ & $\eta_{f^{-} f^{-}}\left[\delta\left(r-r^{\prime}\right)\right]^{\mathrm{b}}$ & $\eta_{f^{+} f^{+}}\left[\delta\left(r-r^{\prime}\right)\right]^{\mathrm{b}}$ & $\eta_{f^{0} f^{0}}\left[\delta\left(r-r^{\prime}\right)\right]^{\mathrm{b}}$ & Exp. $^{\text {a,c }}$ \\
\hline $\mathrm{Li}^{+}$ & 70.6 & 70.3 & 0.73612 & 0.00208 & 0.19305 & 70.2 \\
\hline $\mathrm{Na}^{+}$ & 44.2 & 43.5 & 0.37459 & 0.00137 & 0.09492 & 42.2 \\
\hline $\mathrm{K}^{+}$ & 27.9 & 27.4 & 0.06390 & 0.00074 & 0.01642 & 27.2 \\
\hline $\mathrm{Be}^{2+}$ & 136.1 & 135.1 & 1.75970 & 0.01022 & 0.47655 & 135.6 \\
\hline $\mathrm{Mg}^{2+}$ & 67.2 & 66.0 & 0.55269 & 0.00459 & 0.14235 & 45.0 \\
\hline $\mathrm{Ca}^{2+}$ & 39.8 & 39.1 & 0.09007 & 0.00206 & 0.02375 & 39.4 \\
\hline $\mathrm{Al}^{3+}$ & 93.9 & 92.5 & 0.79781 & 0.00956 & 0.20838 & 91.6 \\
\hline $\mathrm{Ga}^{3+}$ & 37.6 & 36.4 & 0.43968 & 0.01059 & 0.11575 & 33.2 \\
\hline $\mathrm{BF}_{3}$ & 19.5 & 17.6 & 0.03360 & 0.00083 & 0.00825 & 19.4 \\
\hline $\mathrm{BCl}_{3}$ & 13.8 & 12.2 & 0.00860 & 0.00973 & 0.00438 & 11.2 \\
\hline $\mathrm{BBr}_{3}$ & 12.5 & 10.8 & 0.01118 & 0.00807 & 0.00473 & 9.8 \\
\hline $\mathrm{AlF}_{3}$ & 17.8 & 15.4 & 0.02762 & 0.00234 & 0.00728 & 11.8 \\
\hline $\mathrm{AlCl}_{3}$ & 13.4 & 12.5 & 0.00789 & 0.00249 & 0.00251 & - \\
\hline $\mathrm{AlBr}_{3}$ & 12.3 & 11.1 & 0.01202 & 0.00163 & 0.00351 & - \\
\hline $\mathrm{F}_{2}$ & 19.8 & 14.6 & 0.05069 & 0.06496 & 0.02331 & 12.6 \\
\hline $\mathrm{Cl}_{2}$ & 12.7 & 10.7 & 0.01233 & 0.01115 & 0.00563 & 9.2 \\
\hline $\mathrm{Br}_{2}$ & 10.8 & 9.5 & 0.00944 & 0.00730 & 0.00429 & 8.0 \\
\hline $\mathrm{CO}_{2}$ & 16.3 & 18.6 & 0.03044 & 0.02812 & 0.01596 & 17.6 \\
\hline $\mathrm{SO}_{3}$ & 15.1 & 11.9 & 0.01694 & 0.00583 & 0.00537 & 11.0 \\
\hline $\mathrm{SO}_{2}$ & 13.1 & 11.7 & 0.01600 & 0.01323 & 0.00687 & 11.2 \\
\hline
\end{tabular}

\footnotetext{
${ }^{\mathrm{a}}$ units in $\mathrm{eV}$.

${ }^{\mathrm{b}}$ units are atomic units.

c experimental values from Refs. [3,63,64] obtained using Eq. (3).
} 